\title{
Understanding of The "Combat"Requirements, Deepen Reform of Serving Officers Teaching
}

\author{
Wenxiu Wang \\ Naval Aviation Engineering College Qingdao Campus \\ Qingdao, China \\ wwx119@126.com \\ Ruili Zhang \\ Naval Aviation Engineering College Qingdao Campus \\ Qingdao, China \\ zrlhao@163.com
}

\author{
Kui Huang \\ Naval Aviation Engineering College Qingdao Campus \\ Qingdao, China \\ huangkui@163.com \\ Yang Liu \\ Naval Aviation Engineering College Qingdao Campus \\ Qingdao, China
}

\begin{abstract}
This paper studies "combat" teaching method in the teaching of serving officers. First, teachers should set up the idea of "teaching for war" through promoting teaching training closer to the forces and teaching cohesion forces training. And then, we have realized "combat" in teaching content, teaching methods, and evaluation mode. Our reform is located in the forefront compared with the similar colleges and universities. The results are valuable references for the post office educational institutions.
\end{abstract}

Keywords-Combat; Serving Officers; Teaching and Training Teaching Reform

\section{INTRODUCTION}

Teaching and training is the key to the education of serving officers and the important guarantee of teaching quality. To implement the instruction spirit of "winning the war" and "two close" of military headquarters and further enhance education level of serving officers, we need formal characteristics of the education teaching system serviceman teaching and training and the comprehensive reform and innovation from contents to teaching methods on the basis of scientific understanding essence and requirements of the "combat"[1].

\section{A. Deeply Understand the Connotation of the Combat,} Accurately Grasp the Eessence and Requirements of the Combat

"Combat" mainly refers to closely connect the improvement of combat ability in forces with the college education, especially with the demand of qualified talent training and services level. It strengthens the concept of teaching for war, in accordance with "strict in forces, higher than the forces", promotes teaching training closer to the forces and integrates with forces training in order to transfer students' knowledge, manners and ability to the ability of working. The ultimate goal of combat is to improve battle effectiveness and combat ability of the forces[2].

In serving officers training, we should emphasize on the "combat" in teaching, the "standardization" in teaching management, and the "branding" in teaching construction. To be more specific, the combat in teaching is essential to "focus on combat, close to the forces", and it is the core of "standardization" in teaching management and "brand" in teaching construction. Then, "normalization" in teaching management is related to the quality of military students and is the important guarantee to "combat" teaching. We cultivate personnel for aviation equipment technical support, so the teaching must have characteristics of aviation equipment in teaching and management to obtain the "high-quality goods", Therefore, "branding" in teaching construction is a perfect embodiment of "combat" in teaching and "standardization" in management, a construction goal of "combat" and "standardization" as well. While to achieve the goal of "branding" in teaching construction, teaching management must be "standardization". Thus the "normalization" in teaching management is the premise of "branding "in teaching building.

\section{B. Focus on the Characteristics of the Serving Officers,Establish Reform Objectives of Teaching.}

With the reform deepening of military academy education, the educational training shows an increasing trend of training serving officers with different levels, subjects, occupational positions and length of schooling. In general, the officers in the aeronautical equipment support and control department have served as forces more than 10 years[3]. They have sound professional backgrounds, rich experience in the practice of aviation equipment support and excellent ability of solving actual problem in aviation equipment support. Besides, they all have profound knowing and understanding in the fields of aviation equipment management and security which are considered to be quite different from those of reserve officer in teaching.

If we want to achieve "combat" in serving officers teaching, we must make efforts based on the core of "combat". According to the characteristics of serving officers education, we should concentrate on "combat" teaching construction and set the objectives of enhancing students "combat" ability to 
incumbent teaching reform completely. Putting it in detail, first of all, teaching contents should be close to the unit and combat while teachers must track forces equipment and technology development in time. This measure assures that that the troop construction, combat training, equipment development and college research results can be added in enrich teaching as quickly as possible. Secondly, teaching methods should be diversified, such as examples in teaching, supposing assignments, case teaching and exercise that are helpful to combat content and generate actual combat ability. Additionally, the checking standards should be connected to military life and combats[4]

\section{RELYING ON THE FORCE, REALIZATION OF THE TEACHING CONTENT "COMBAT"}

\section{A. Open Channels, Combing Force Security Problems}

In the first place, we need to use the opportunities provided for students visiting troops as well as the investigations and surveys in research projects to figure out current situation of aviation forces and collect problems of forces in aviation equipment technology directly via questionnaires or discussions. In the second place, we can make indirect collections by discussion or tutorials among students. As it was mentioned before, the serving officers generally have worked more than 10 years in forces and have strong professional knowledge, rich experience in the practice of aviation equipment support, ability of solving actual problem and a profound understanding to aviation equipment management. Under teaching, we should follow up the principles of "learning with questions, solving problems and leaving "[5]. Moreover, we have to understand problems needed to be solved in the army from the perspective of the students and integrate those into the classroom. This measure makes teaching content closer to the training positions demand, and improves the pertinence and practicality of the teaching content.

\section{B. Lead From the Problem, Problem of Troops Bring to the Classroom}

In the organization of the teaching content, we need to be close to the position requirements for the students to organize the teaching content by analyzing the practical problems of aviation equipment support in forces. Furthermore, the more important thing for the teachers is to set up the bridge of aviation equipment support theory and aviation equipment support and to use the theory of aviation equipment support "vector" to shoot practical problems of "target "[6]. As a result, this can implement the deep integration of the theory and practice, making the teaching more targeted and stimulating the students' subjective initiative.

When it comes to implementation, teachers should organize teaching content with the hot and difficult problems of aviation equipment technology security analysis as layouts. To begin with, it is better for teachers to use practical problems such as the breakthrough points to find out the underlying theory, and then use the theory methods to solve the practical problems in aviation equipment technical support. Finally, students will be encouraged to put forward the practical problems in their work, construct, analyze and even discuss concrete examples using the theory teaching methods. This measure can fully stimulate the students' subjective initiatives and cultivate their ability to solve practical problems using the theory of aviation equipment technology security.

\section{According to a Comprehensive Exercise, Implement "Combat" in Teaching Methods}

Due to the requirements in the teaching outline, it is necessary to provide simulated exercises of the major aviation maintenance support, organizational processes and the methods of command support in the students' future jobs. What's more, we have to improve students' ability of wartime security organization and execution to satisfy the real demands in the future.

1) On the basis of combat demand, set up practice content scientifically.

As for the content setting, teachers should start from the practical needs and rely on a certain combat scenarios of guarantee system. However, the more important thing is to focus on difficult problems of exercise wartime maintenance support and organize implementation procedures of aviation maintenance, for example flight transit, plane, security personnel, equipment and allocate, the determination of security level, work process and content, plane fly, emergency, aircraft rescue in aviation equipment, etc. Apparently, these courses should be added into the practice content to raise students' ability of security command and management in wartime.

2) Mission drives combat, elaborates organization integrated exercise.

Simulated exercise is actually a mission driving, it organizes and implements exercise with a main line of completing a mission in terms of the operation command process. Specifically, it involves the overall process from the previous operations, task delivery and corresponding task arrangement to preparations, action and the organization and implementation until the end of the war. In the process of completing combat missions, students can obtain preliminary experience in the future jobs, and master organization command procedure, method and content of wartime guarantee system.

\section{INNOVATION EVALUATION METHOD, REALIZE ASSESSMENT OF "COMBAT"}

In fact, the examine of theory "combat" is the assessment of students' comprehensive military accomplishment as well as their ability to ask questions, analyze and solve problems. Absolutely, it is difficult to judge the officers with a single test, so we implement the examination combined of "full program evaluation", "open evaluation" and replacement of acting.

\section{A. "Overall Process Evaluation",Assessment of Students Comprehensive Quality}

In training of serving officers, "discussion", "case analysis" and " practical ", and consistently account for large 
proportions and are emphasized throughout the teaching process. To strengthen the management and guarantee the teaching effect, we implement "the whole program evaluation", including discussion in ordinary, performance of case study and learning attitude. Thus we can evaluate the comprehensive performance of students.

\section{B. "Open Evaluation ", Ask Questions, Analysis and Solving Skills are Emphasis}

"Open evaluation" represents that we can use different ways of assessing in terms of different teaching contents. In addition, the examine contents and evaluation ways are flexible and open. For example, theoretical courses should be used by case analysis which is equal to students making a big job. When it comes to analysis topic, on the one hand, teachers give problems according to the key and difficulty point of aviation equipment technical support, such as "application analysis of RCM in aviation equipment maintenance", "application analysis of overall planning method in aviation equipment technology security"," wounded repair technology and process analysis in aviation equipment ","data prediction technology and application in aviation equipment maintenance ", "optimization analysis of warehouse location proposition " and so on. On the other hand, Students can also combine their own actual work with analysis and solve question according to the learned knowledge. This can fully embody the students individual differences, and reflects the students' ability to analyze and solve problems, hence, achieves the goal of improving aviation equipment technical support capability.

\section{C. "To Exercise Instead of Test", Enhancement of Students Practical Ability Assessment}

Comprehensive military drill is definitely a collection of research, demonstration and examine (assessment). It links the knowledge to army equipment safeguard with demonstration through simulation. Thanks to this inspection way, students will be more familiar with aviation maintenance safeguard procedures and content of the "real" process, and they are likely to have a solid foundation for future jobs through exercises aviation maintenance safeguard command and management ability. During the process of practice, teachers and military experts assess whether or not students are qualified by office commanding and management ability efficiency. They evaluate the students with strict requirements, appraisals and tough assessments, consequently highlighting the outstanding characteristics of education.

\section{CONCLUSION}

The combat teaching of serving officers concentrates on the educational characteristics of the officers and further makes the combat teaching material, teaching idea, teaching content, teaching means and teaching focus, teaching mode, teaching support and teaching management closer to reality. Therefore, the students' academic background, quality and ability can meet the standards of army combat and training and the demands of officers in the task. Moreover, it is much possible to realize that education training means "focus on combat, close to the forces", to promote quality of educational training for serving officers and to lay a good foundation to improve the battle ability.

\section{REFERENCES}

[1] Shujun Guo, several considerations of officers in service training teaching [J]. Journal of shijiazhuang institute of mechanized, 2011 (5) : 54.

[2] Xianbin Song, discussion of officers in service professional education examination reform [J]. Journal of armored force academic, 2012 (5) : 56.

[3] xiaoping zhang . Military theory course should vigorously promote examples in teaching [J]. Journal of higher education research, 2010 (2) : 109.

[4] Hao Zhou, research of teaching key points in implementing case of intermediate professional command[J]. Journal of higher education research, 2011 (3) : 67.

[5] Feng Yue,The current problems and countermeasures of college's comprehensive practice [J]. Journal of xi 'an army college, 2007 (4): 72.

[6] Linyuan Bai , discussion of Comprehensive exercise in airborne troops[J]. Journal of guilin air force academy, 2003, (6): 60 